\title{
Protein Phosphatase 1 Regulates the Histone Code for Long-Term Memory
}

\author{
Kyoko Koshibu, ${ }^{1 \star}$ Johannes Gräff, ${ }^{1 \star}$ Monique Beullens, ${ }^{3}$ Fabrice D. Heitz, ${ }^{1}$ Dominik Berchtold, ${ }^{1,2}$ Holger Russig, ${ }^{1}$ \\ Mélissa Farinelli, ${ }^{1}$ Mathieu Bollen, ${ }^{3}$ and Isabelle M. Mansuy ${ }^{1}$ \\ ${ }^{1}$ Brain Research Institute, Medical Faculty of the University of Zürich and Department of Biology of the Swiss Federal Institute of Technology, and ${ }^{2}$ Institute \\ for Human Movement Sciences and Sport, Department of Biology of the Swiss Federal Institute of Technology, CH-8057 Zurich, Switzerland, and \\ ${ }^{3}$ Laboratory of Biosignaling and Therapeutics, Department of Molecular Cell Biology, University of Leuven, B-3000 Leuven, Belgium
}

Chromatin remodeling through histone posttranslational modifications (PTMs) and DNA methylation has recently been implicated in cognitive functions, but the mechanisms involved in such epigenetic regulation remain poorly understood. Here, we show that protein phosphatase 1 (PP1) is a critical regulator of chromatin remodeling in the mammalian brain that controls histone PTMs and gene transcription associated with long-term memory. Our data show that PP1 is present at the chromatin in brain cells and interacts with enzymes of the epigenetic machinery including HDAC1 (histone deacetylase 1) and histone demethylase JMJD2A (jumonji domaincontaining protein $2 \mathrm{~A}$ ). The selective inhibition of the nuclear pool of PP1 in forebrain neurons in transgenic mice is shown to induce several histone PTMs that include not only phosphorylation but also acetylation and methylation. These PTMs are residue-specific and occur at the promoter of genes important for memory formation like CREB (cAMP response element-binding protein) and NF- $\kappa \mathrm{B}$ (nuclear factor- $\kappa \mathrm{B}$ ). These histone PTMs further co-occur with selective binding of RNA polymerase II and altered gene transcription, and are associated with improved long-term memory for objects and space. Together, these findings reveal a novel mechanism for the epigenetic control of gene transcription and long-term memory in the adult brain that depends on PP1.

\section{Introduction}

Chromatin remodeling is an important epigenetic mechanism for the regulation of gene transcription (Jaenisch and Bird, 2003; Williams and Tyler, 2007). In the brain, it was recently demonstrated to be critical for learning, the formation of long-term memory (LTM) (Guan et al., 2002; Alarcón et al., 2004; Levenson et al., 2004; Chwang et al., 2006, 2007; Fischer et al., 2007; Miller and Sweatt, 2007; Miller et al., 2008), the maintenance of neuronal plasticity (Duman and Newton, 2007), and neuroadaptation in depression (Tsankova et al., 2007). Chromatin remodeling is a process that dynamically regulates the accessibility of the DNA to the transcriptional machinery, through nuclear mechanisms involving posttranslational modifications (PTMs) of histone proteins and DNA methylation. Both histone PTMs and DNA methylation are

\footnotetext{
Received July 26, 2009; revised Sept. 1, 2009; accepted Sept. 4, 2009.

This work was supported by the University of Zurich, the Swiss Federal Institute of Technology, the Swiss National Science Foundation, the National Center for Competence in Research "Neural Plasticity and Repair," the Human Frontier Science Program, European Molecular Biology Organization, the Novartis Research Foundation, and the Slack Gyr Foundation. We thank Sandor Vizi, Tamara Franklin, and Hansjörg Kasper for technical support, Shihori Yokobayashi and Antoine Peters for help and guidance with ChIP assays, Shiva Tyagarajan for help with co-IP analyses, Didier Trono for lentiviral constructs, Gregor Fischer for help with the mouse colony, and Eva Hochreutener and Roland Schöb for help with the figures. The study was initiated by K.K. and I.M.M., expanded by J.G. and I.M.M., and experimentally performed essentially by K.K. and J.G. Tet0-NIPP1* mice were generated by K.K. Behavior was run by J.G., K.K., D.B., and H.R.; RT-PCR and Western blots by J.G. and K.K.; phosphatase assay and IHC by K.K.; qRT-PCR, HDAC activity, and co-IP and ChIP assays by J.G.; lentivirus-mediated overexpression of PP1 $\gamma$ by J.G., F.D.H., and M.F.; and in vitro assays by M. Beullens and M. Bollen. This manuscript was prepared by K.K., J.G., and I.M.M., and essentially written by J.G. and I.M.M.

*K.K. and J.G. contributed equally to this work.

Correspondence should be addressed to Isabelle M. Mansuy at the above address. E-mail: mansuy@hifo.uzh.ch. D01:10.1523/JNEUROSCI.3610-09.2009

Copyright $\odot 2009$ Society for Neuroscience $\quad 0270-6474 / 09 / 2913079-11 \$ 15.00 / 0$
}

induced by complex enzymatic machineries engaged in multiple cross talks that establish a gene-specific histone code determining whether a gene is activated or repressed (Jenuwein and Allis, 2001; Kouzarides, 2007; Latham and Dent, 2007; Li et al., 2007).

Previous work has shown that histone phosphorylation and acetylation are associated with the consolidation of associative memory such as contextual fear and taste memory (Swank and Sweatt, 2001; Guan et al., 2002; Alarcón et al., 2004; Korzus et al., 2004; Levenson et al., 2004; Chwang et al., 2006, 2007; Bredy et al., 2007; Lubin and Sweatt, 2007; Vecsey et al., 2007; Lubin et al., 2008). While histone acetylation is known to be mediated by histone acetyltransferases (HATs) like cAMP response elementbinding protein-binding protein (CBP) (Alarcón et al., 2004; Korzus et al., 2004) and p300 (Oliveira et al., 2007), and by histone deacetylases (HDACs) (Levenson et al., 2004; Vecsey et al., 2007), histone phosphorylation engages the protein kinases mitogen- and stress-activated protein kinase 1 (MSK1) (Chwang et al., 2007) and extracellular signal-regulated kinase (ERK)/ mitogen-activated protein kinase (MAPK) (Chwang et al., 2006). However, the protein phosphatase(s) that dephosphorylate histones in the adult brain during memory formation have to date not been identified. This is a major shortcoming because protein phosphatases (PPs) are essential counterparts to protein kinases in the regulation of the phosphorylation of numerous substrates. Moreover, PPs are strong molecular constraints on learning and memory (Lee and Silva, 2009) that favor forgetting (Genoux et al., 2002) and play a role in Alzheimer's disease (Knobloch et al., 2007) and cognitive decline in aging (Genoux et al., 2002; Mansuy and Shenolikar, 2006; Knobloch et al., 2007). 
Among the several PPs expressed in the nervous system, protein Ser/Thr phosphatase 1 (PP1) is one of the most likely candidates to be involved in chromatin remodeling in the adult brain. In vitro, $\mathrm{PP} 1$ is an important regulator of transcriptional and translational events such as mRNA processing, splicing, and translation initiation in several cell types (Bennett, 2005; Mansuy and Shenolikar, 2006; Moorhead et al., 2007). On a subcellular level, it is abundant in the nucleus in which it forms distinct multimeric holoenzymes with specific targeting partners and thereby regulates substrates involved in nuclear processes (Bennett, 2005). In yeast, Caenorhabditis elegans, and Xenopus during mitosis, PP1 controls histone 3 (H3) dephosphorylation and can thereby reverse the action of Aurora protein kinases (Hsu et al., 2000; Murnion et al., 2001). In dividing kidney cells, PP1 also influences histone acetylation, through its ability to form a complex with HDAC1 and recruit it to the chromatin (Canettieri et al., 2003; Jin et al., 2003; Brush et al., 2004). Little is known, however, about the role of PP1 in the control of histone PTMs in postmitotic cells such as adult neurons, in particular in the context of memory formation. Here, we provide new evidence that PP1 is a key regulator of histone PTMs in adult neurons that is essential for the establishment of gene-specific histone codes and the control of gene transcription in long-term memory formation.

\section{Materials and Methods}

\section{Animals}

Transgenic mice carrying a fragment of the nuclear inhibitor of PP1 spanning amino acids 143-224 (NIPP1*), excluding other functional domains of endogenous NIPP1, fused to enhanced green fluorescent protein (EGFP) and linked to a tetO promoter were generated and crossed with mice expressing the reverse tetracycline-controlled transactivator 2 (rtTA2) under the control of the forebrain-specific $\mathrm{Ca}^{2+} / \mathrm{CaM}-$ dependent protein kinase II $\alpha$ (CaMKII $\alpha$ ) promoter (Michalon et al., 2005) to obtain double transgenic animals. For all experiments, adult (3-8 months of age) NIPP $1^{*}$-EGFP transgenic males fed with doxycycline (dox) (6 mg per gram of food for at least $8 \mathrm{~d}$; Westward Pharmaceuticals) were used. As controls, we used littermates carrying no transgene or either one of the transgenes fed with dox, or NIPP $1^{\star}$-EGFP mice not fed with dox. For on/off experiments, mice were treated with dox for at least $8 \mathrm{~d}$, and then dox was withdrawn and mice were tested a minimum of $7 \mathrm{~d}$ later. Mice were maintained in accordance with the Federation of Swiss Cantonal Veterinary Office and European Community Council Directive (86/609/EEC) guidelines.

\section{Reverse transcription-PCR}

Total RNA was isolated with TRI Reagent (Research Center) and purified with RQ1 DNase (Promega), followed by precipitation with sodium acetate and ethanol. Reverse transcription was performed with $1 \mu \mathrm{g}$ of total RNA using an Enhanced Avian HS reverse transcription (RT)-PCR kit (Sigma-Aldrich).

\section{Immunohistochemistry}

Free-floating sections of transcardially perfused animals were incubated with the following antibodies: GFP (1:500; Invitrogen), neuronal nuclei (NeuN) (1:500; Sigma-Aldrich), and Cy3 goat anti-rabbit or FITC donkey anti-mouse (1:500; Jackson ImmunoResearch Laboratories). Nuclear staining was performed using $4^{\prime}, 6^{\prime}$-diamidino-2-phenylindole (DAPI) or hematoxylin. Organotypic hippocampal slices were doubleimmunostained for EGFP expression and NeuN. Slices were fixed overnight at $4^{\circ} \mathrm{C}$ in $4 \%$ paraformaldehyde in $0.1 \mathrm{~m}$ phosphate buffer (PB), $\mathrm{pH}$ 7.4, washed in $0.1 \mathrm{M} \mathrm{PB}$ (three times $1 \mathrm{~h}$ ), and then blocked and permeabilized in $0.1 \mathrm{M} \mathrm{PB}, 0.4 \%$ Triton $\mathrm{X}-100$, and $10 \%$ heat-inactivated horse serum (HS) for $24 \mathrm{~h}$ at $4^{\circ} \mathrm{C}$. Slices were incubated in primary antibodies against GFP (1:1000; rabbit; Synaptic Systems) and NeuN (1:1000; mouse; Millipore Bioscience Research Reagents) for $72 \mathrm{~h}$ at $4^{\circ} \mathrm{C}$ in $0.1 \mathrm{M}$ $\mathrm{PB}, 0.4 \%$ Triton $\mathrm{X}-100$, and $10 \% \mathrm{HS}$, followed by overnight incubation with goat anti-rabbit FITC and donkey anti-mouse TRITC (tetramethylrhodamine isothiocyanate) fluorescence-conjugated secondary antibodies (1:1000; Jackson ImmunoResearch Laboratories). All images were acquired with a CoolSNAP digital camera (Roper Scientific) and an Axiophot microscope (Zeiss) and analyzed using MCID Elite 7.0 software (MCID).

\section{Protein phosphatase assay}

Protein phosphatase assays were performed as previously described (Hédou et al., 2008). In brief, hippocampi were dissected and homogenized in $3.75 \mathrm{~mm}$ Tris-HCl, pH 7.4, $15 \mathrm{~mm} \mathrm{KCl}, 3.75 \mathrm{~mm} \mathrm{NaCl}, 250 \mu \mathrm{M}$ EDTA, $50 \mu \mathrm{M}$ EGTA, 30\% (w/v) sucrose, 30\% (v/v) glycerol, protease inhibitor mixture (Sigma-Aldrich), $100 \mu \mathrm{M}$ PMSF using a Dounce homogenizer, and then centrifuged $(1000 \times g ; 10 \mathrm{~min})$. Supernatant (cytoplasmic fraction) and pellet (nuclear fraction) were separated. Each fraction was resuspended in the same buffer without sucrose but with $15 \mathrm{~mm}$ $\beta$-mercaptoethanol, homogenized using a $26 \mathrm{G}$ syringe, and then purified on PiResin (Innova Biosciences). Phosphatase activity was determined by incubating $2 \mu \mathrm{g}$ sample with $0.15 \mathrm{~mm}$ RII substrate (BIOMOL) and $5 \mathrm{~nm}$ tautomycin (to inhibit PP1) or 5 nм tautomycin plus okadaic acid (OA) (to inhibit PP1 and PP2A activity) in $50 \mathrm{~mm}$ Tris- $\mathrm{HCl}, \mathrm{pH}$ 7.0, $100 \mu \mathrm{M} \mathrm{Na}{ }_{2}$ EDTA, $5 \mathrm{~mm}$ DTT, and $0.01 \%$ Brij 35 at $30^{\circ} \mathrm{C}$ for $10 \mathrm{~min}$. The reaction was terminated by adding TCA followed by centrifugation $(13,000 \times g ; 5 \mathrm{~min})$. The amount of free phosphates released in the reaction was measured with BIOMOL Green reagent (BIOMOL) at 620 $\mathrm{nm}$ and background subtracted. For total phosphatase activity, tautomycin and OA were removed from the reaction. PP1 and PP2A activity was calculated by the ratio of phosphatase activity with inhibitors and total phosphatase activity.

\section{Coimmunoprecipitation}

In vitro. Homogenates from N2A (murine neuroblastoma cells) cells grown in DMEM (containing 10\% fetal calf serum) were centrifuged for $10 \mathrm{~min}$ at $10,000 \times \mathrm{g}$, and lysates were used for immunoprecipitation. Anti-HDAC1 antibody (Abcam) was added for $1 \mathrm{~h}$ at $10^{\circ} \mathrm{C}$, followed by incubation with protein A-Sepharose for another hour. Precipitates were washed once with TBS (20 mm Tris- $\mathrm{HCl}$ at pH 7.4 plus $150 \mathrm{~mm} \mathrm{NaCl}$ ) containing $0.1 \mathrm{M} \mathrm{LiCl}$, twice with TBS supplemented with $0.1 \%$ $\mathrm{NP}-40$, and finally with $20 \mathrm{~mm}$ Tris- $\mathrm{HCl}$ at $\mathrm{pH} 7.4$ supplemented with 1 mM DTT and $0.1 \mathrm{mg} / \mathrm{ml} \mathrm{BSA}$, and analyzed by immunoblotting with antibodies against PP1 $\gamma$ (Calbiochem), HDAC1 (Cell Signaling), and IgG (Sigma-Aldrich).

In vivo. Whole-tissue lysates were prepared by homogenization in 500 $\mu l$ of sterile-filtered $50 \mathrm{~mm}$ Tris, $120 \mathrm{~mm} \mathrm{NaCl}, 0.5 \% \mathrm{NP}-40$ containing proteinase and phosphatase inhibitors (1:100; Sigma-Aldrich), followed by $15 \mathrm{~min}$ centrifugation at $14,000 \mathrm{rpm}$ at $4^{\circ} \mathrm{C}$ and collection of the supernatant. After $60-90$ min incubation with 1-2 $\mu$ g of the corresponding antibody, $20 \mu \mathrm{l}$ of BSA-precleared pansorbin-protein A beads (Calbiochem) were added for $45 \mathrm{~min}$ at $4^{\circ} \mathrm{C}$, and the immune complexes were collected at $8000 \mathrm{rpm}$ for $3 \mathrm{~min}$, by one wash each in high-salt homogenization buffer (containing $50 \mathrm{~mm}$ Tris, $500 \mathrm{~mm} \mathrm{NaCl}$, and 1\% NP-40) and regular homogenization buffer. Finally, samples were loaded on a $10-12 \%$ SDS gel and analyzed (see below, Western blotting). Immunoprecipitation (IP) antibodies used were HDAC1 (Cell Signaling) and PP1 $\gamma$ (Calbiochem), and blotting antibodies used were PP1 (Calbiochem), HDAC1 (Cell Signaling), Jmj-C domain-containing histone demethylation protein 2A (JMJD2A) (Abcam), lysine-specific histone demethylase 1 (LSD1) (Cell Signaling), and IgG (Sigma-Aldrich).

\section{In vitro phosphorylation assay}

Recombinant histone H3 (Roche) was phosphorylated by addition of the catalytic subunit of protein kinase A (Sigma-Aldrich), and then incubated with or without the catalytic subunit of PP1, PP1 $\gamma$ (purified from rabbit skeletal muscle), and a NIPP1 peptide (Beullens et al., 1992). At indicated time points, aliquots were collected, boiled in SDS lysis buffer, and run by SDS-PAGE. The gel was stained with Coomassie blue, and membranes were incubated with anti-phospho H3S10 (Millipore) as described below. 
a

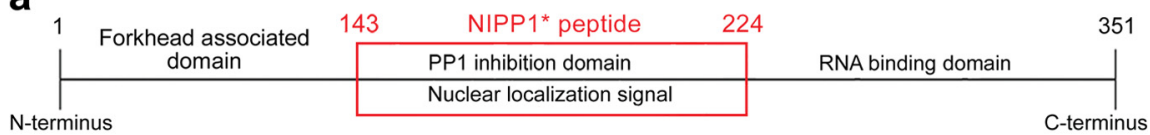

b

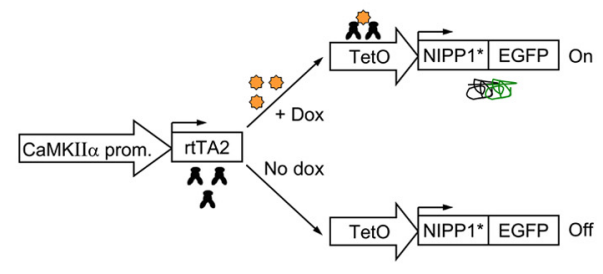

d
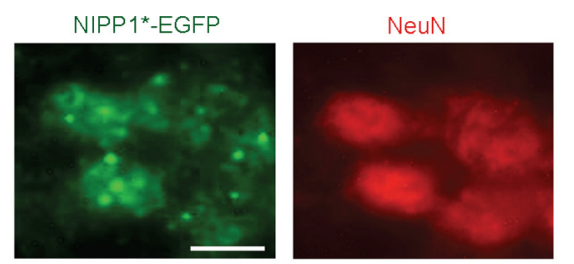

NIPP1*-EGFP/NeuN

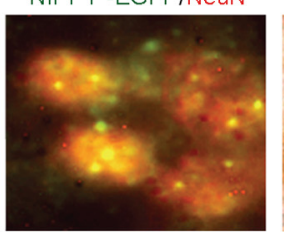

NIPP1*-EGFP/Hemat

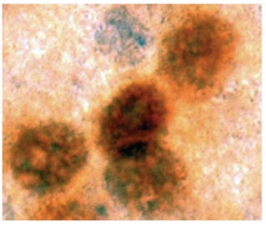

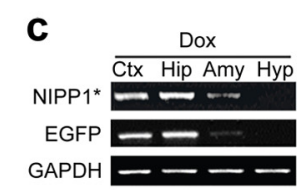

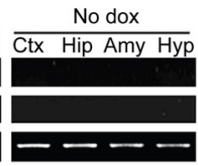

e

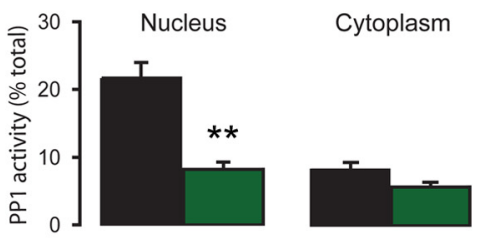

Figure 1. Inducible and neuron-specific inhibition of nuclear PP1 in the adult mouse forebrain. $\boldsymbol{a}$, Schematic representation of the NIPP1* fragment containing the PP1 inhibitory domain and nuclear localization signal (amino acids 143-224; red box) expressed as a transgene. $\boldsymbol{b}$, Schematic of the transgenes used to express NIPP1* inducibly in forebrain neurons. NIPP1*-EGFP expression is induced by doxycycline (Dox) (On). c, RT-PCR examining NIPP1* and EGFP expression in cortex (Ctx), hippocampal formation (Hip), amygdala (Amy), and hypothalamus (Hyp) in adult mutant mice treated with dox or not. $\boldsymbol{d}$, Immunohistochemical staining showing NIPP1*-EGFP colocalization with the neuronal marker NeuN in nuclei (NIPP1*-EGFP, green/NeuN, red), and nuclear counterstaining with hematoxylin (NIPP1*-EGFP, brown/Hemat, blue). Scale bar, $20 \mu \mathrm{m}$. $\boldsymbol{e}$, Decreased PP1 activity in nuclear $(n=7)$ but not cytoplasmic $(n=5)$ hippocampal extracts from NIPP1*-EGFP mice compared with control littermates (nuclear, $n=11$; cytoplasmic, $n=7$ ). Nuclear PP1 activity, $F_{(1,15)}=11.24,{ }^{* *} p<0.01$; cytoplasmic activity, $F_{(1,12)}=1.14, p=$ 0.31. Error bars indicate SEM.

\section{HDAC activity assay}

HDAC activity in hippocampal nuclear extracts $(50 \mu \mathrm{g})$ was determined using a colorimetric HDAC Activity Assay kit (Abcam) and expressed as optical density value at $405 \mathrm{~nm} / \mu \mathrm{g}$ protein. Activity in control samples was used for normalization.

\section{Western blotting}

Ten to $15 \mu \mathrm{g}$ proteins from nuclear extracts or membrane-enriched hippocampal preparations were prepared from freshly dissected brain as described above (see Protein phosphatase assay) resolved on 10$12 \%$ SDS-PAGE, and transferred onto a nitrocellulose membrane (BioRad). Membranes were blocked (Rockland IR blocking buffer; Rockland), and then incubated in primary and secondary antibodies. Band intensity was determined and quantified using an Odyssey IR scanner (LI-COR Biosciences). The signal was normalized to $\mathrm{H} 1.0$ for histone proteins and $\beta$-actin for non-nuclear proteins. Values in NIPP $1^{*}$ transgenic mice were normalized to values in control littermates. The following antibodies were used: H2B (1:2000) (Abcam), H3 (1:2000), H4 (1: 2000) (Millipore); phospho H3T3 (1:1000), phospho H3T11 (1:1000), phospho H3S28 (1:1000), acetyl H2B (1:10,000) (Abcam); phospho H3S10 (1:1000), acetyl H3K9 (1:1000), acetyl H3K14 (1:2000), acetyl H4K5 (1:1000) (Millipore); dimethyl H3K4 (1:2000), trimethyl H3K36 (1:2000) (Abcam); cAMP response element-binding protein (CREB) (1: 1000), phospho CREB S133 (1:1000) (Cell Signaling); ERK1+2 (1:1000), phospho ERK1+2 T185+T202 (1:2000), HDAC1 (1:1000), phospho HDAC1 S421 (1:1000), MSK1 (1:1000), phospho MSK1 T581 (1:1000) (Abcam); methyl-CpG-binding protein 2 (MeCP2) (1:2000), phospho MeCP2 S421 (1:2000) (generously provided by M. Greenberg, Harvard University, Cambridge, MA); GluR1 (1:1000), GluR2 (1:1000), CaMKII $\alpha$

(1:5000), phospho GluR1 S845 (1:1000), phospho GluR2 S880 (1:1000), phospho CaMKII $\alpha$ S246 (1:5000) (Millipore); H1.0 (1:1000) (Abcam); $\beta$-actin (1:4000) (Sigma-Aldrich); goat anti-rabbit (IRDye $680 \mathrm{~nm} ; 1: 10,000)$ and goat anti-mouse (IRDye $800 \mathrm{~nm} ; 1: 10,000$ ) (LI-COR Biosciences).

\section{Quantitative RT-PCR}

Total RNA was extracted using the NucleoSpin Kit II (Macherey-Nagel), purified with RQ1 DNase (Promega), and reverse-transcribed using the SuperScript First-Strand Synthesis System for RT-PCR II (Invitrogen). Quantitative PCR was performed using TaqMan probes (Applied Biosystems) and an Applied Biosystems 7500 Thermal Cycler. Each sample was quantified three times, and equal amounts of cDNA were analyzed in triplicate for each run. Values were chosen in the linear range of amplification and the comparative Ct method was used to assess differences in gene expression between samples (Livak and Schmittgen, 2001). $\beta$-Actin was used as internal control.

\section{Lentivirus preparation and injection in hippocampal slices}

For neuron-specific expression of $\mathrm{PP} 1 \gamma$, the lentiviral vector pLVPRT-tTRKRAB (Szulc et al., 2006) (kindly provided by D. Trono, Swiss Federal Institute of Technology, Lausanne, Switzerland) was used to generate pLVPRTtTRKRAB-PP1 $\gamma$-EGFP. PP1 $\gamma$ fused to EGFP (PP1 $\gamma$-EGFP) was excised from pEGFP-C1PP1 $\gamma$ (Ceulemans et al., 2002) (obtained from S. Shenolikar, Duke University, Durham, NC) and subcloned between the MluI and SmaI sites of pLVPRT-tTRKRAB. The construct was sequenced before proceeding to the PP1 $\gamma$ EGFP virus production as previously described (Szulc et al., 2006). Virus was titrated by physical particle determination with a p24 ELISA test (HIV-1 P24 ELISA; NEK050; PerkinElmer). Organotypic hippocampal slices from NIPP1*-EGFP mutant and control mice were cultured in vitro using the roller tube technique. After 2 weeks in culture, the slices were injected with PP1 $\gamma$-EGFP viral solution $\left(\sim 1.15 \times 10^{9} \mathrm{TU} /\right.$ $\mathrm{ml}$ ) or artificial CSF (aCSF) as control. Typically, each slice was injected 5-10 times with $2 \mu \mathrm{l}$ of the virus solution/aCSF. After injection, slices were returned to the roller tubes and supplemented with penicillin/streptomycin (1:500) for at least 1 week. On the day before additional processing, the culture medium was replaced with medium containing $1 \mu \mathrm{g} / \mathrm{ml}$ doxycycline to induce PP1 $\gamma$-EGFP expression.

\section{Chromatin immunoprecipitation}

Chromatin immunoprecipitation (ChIP) was performed as described by Tsankova et al. (2004) with the following modifications. After crosslinking, samples were spun down at $1500 \mathrm{rpm}$ for $5 \mathrm{~min}$ at $4^{\circ} \mathrm{C}$, and the pellet was washed twice with ice-cold PBS containing proteinase inhibitors (Complete; Roche). Samples were then homogenized in cell lysis buffer containing proteinase and phosphatase inhibitors ( $1 \mathrm{~mm} \beta$-glycerophosphate, $10 \mathrm{~mm} \mathrm{NaF}, 0.1 \mathrm{~mm} \mathrm{Na}_{3} \mathrm{VO}_{4}$ ) with 10 strokes on ice in a Dounce homogenizer, and then in nuclear lysis buffer containing the same proteinase and phosphatase inhibitors by pipetting. Samples were sonicated on ice using a Branson Digital Sonifier with 15 cycles at $50 \%$ power setting of $10 \mathrm{~s}$ each. A total of $100 \mu \mathrm{g}$ per sample was used for each ChIP reaction in IP buffer ( $0.1 \%$ SDS, $1 \%$ Triton X-100, $150 \mathrm{~mm} \mathrm{NaCl}, 2$ mu EDTA, pH 8, 20 mm Tris-Cl, pH 8.0, containing the same inhibitors) and immunoprecipitated overnight at $4^{\circ} \mathrm{C}$ with $5 \mu \mathrm{g}$ of the corresponding antibodies (see above, Western blotting) and anti-IgG (SigmaAldrich) as a negative control. For PP1 $\gamma$ and RNA polymerase II (RNA 
Pol II) ChIP assays, PP1 $\gamma$ (Calbiochem) and RNA polymerase II CTD (YSPTSPS) repeat (Abcam) was used. After IP, DNA-histone complexes were collected with $40 \mu \mathrm{l}$ of $10 \%$ BSA/salmon sperm DNA (Stratagene)precleared protein A/Sepharose beads (GE Healthcare) for $2 \mathrm{~h}$ at $4^{\circ} \mathrm{C}$. The sample/bead mixtures were washed twice with wash buffer $(0.1 \%$ SDS in IP buffer), once with final wash buffer $(0.1 \%$ SDS, $1 \%$ Triton X-100, $0.5 \mathrm{~m}$ $\mathrm{NaCl}, 2$ mm EDTA, pH 8.0, 20 mm Tris-Cl, pH 8.0, containing proteinase inhibitors), and twice with TE (10 mM Tris-Cl, pH 8.0, $1 \mathrm{~mm}$ EDTA). DNA and histones were dissociated by incubation in $1 \%$ SDS in TE for at least $4 \mathrm{~h}$ at $65^{\circ} \mathrm{C}$. Finally, proteins were digested with proteinase $\mathrm{K}$ (Sigma-Aldrich) for $1 \mathrm{~h}$ at $45^{\circ} \mathrm{C}$, and the DNA was extracted with phenol/chloroform/isoamyl alcohol (Fluka) and resuspended in $100 \mu \mathrm{l}$ of TE. ChIP experiments were run at least in biological triplicates. To quantify histone-associated DNA, real-time PCR of IP samples was performed on an Applied Biosystems 7500 Thermal Cycler using gene-specific primers (supplemental Table 1, available at www.jneurosci.org as supplemental material) and SYBR green (QIAGEN) with the following cycling conditions: $15 \mathrm{~min}$ at $95^{\circ} \mathrm{C}, 45$ cycles of $15 \mathrm{~s}$ at $94^{\circ} \mathrm{C}, 30 \mathrm{~s}$ at $60^{\circ} \mathrm{C}$, and $1 \mathrm{~min}$ at $72^{\circ} \mathrm{C}$. Data were collected in the linear amplification range. Relative quantification was estimated as described previously (Chakrabarti et al., 2002) with $\beta$-tubulin and $\beta$-globin as control genes. Each PCR was repeated at least twice.

\section{Behavior}

The novel object recognition task was conducted as previously described (Genoux et al., 2002). Briefly, mice were placed in an arena containing three unknown objects that they explored during 5 sessions of $5 \mathrm{~min}$. Memory for the objects was tested by exposing the animal to two of the now familiar objects and one novel object. Discrimination ratio was calculated as the percentage of exploration of the novel object defined as DR $=t_{\text {novel }} /\left(t_{\text {novel }}+\left(t_{\text {familiar } 1}+\right.\right.$ $\left.\left.t_{\text {familiar2 }}\right)\right)$, where $t_{\text {novel }}$ is the time spent with the novel object (in seconds), and $t_{\text {familiar }}$ is the time spent with familiar objects 1 and 2 (in seconds). For molecular analyses, mice were killed 2 min after their last behavioral session. The Morris water maze was conducted as described previously (Malleret et al., 2001). During training, mice were allowed to swim until they reached the hidden platform or for a maximum of $90 \mathrm{~s}$. If the animals did not find the platform, they were gladly placed on it for $15 \mathrm{~s}$. On testing day, mice were put in the water without the platform for $60 \mathrm{~s}$.

\section{Statistics}

ANOVAs and univariate or multivariate general linearized model were used to determine genotype and treatment effect. Tukey's or least significant difference (LSD) post hoc analyses were conducted when appropriate. ChIP data were analyzed using two-tailed paired $t$ tests. Statistical significance was set at ${ }^{\star} p \leq 0.05,{ }^{* *} p \leq 0.01$, and ${ }^{* *} p \leq 0.001$. All values are expressed as mean \pm SEM.

\section{Results}

\section{Reversible and neuron-specific inhibition of nuclear PP1 in} the adult forebrain

To investigate the functions of PP1 in chromatin remodeling and examine whether it contributes to the epigenetic regulation of b Histone phosphorylation

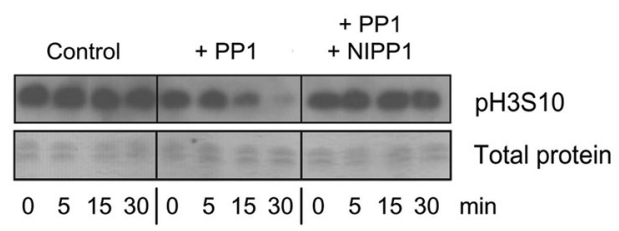

d HDAC activity

Nucleus Cytoplasm
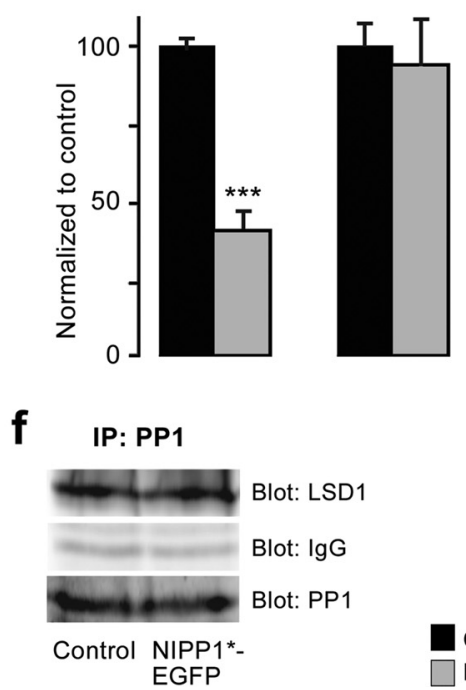

Control NIPP1*-EGFP

Figure 2. Nuclear PP1 interacts with the epigenetic machinery. $\boldsymbol{a}$, Representative Western blot showing coimmunoprecipitation of $\mathrm{H} 3$ and PP1 using a PP1 $\gamma$ antibody in NIPP1*-EGFP mice and control littermates in the adult hippocampus. $\boldsymbol{b}$, Direct dephosphorylation of histone $\mathrm{H} 3$ in vitro. Western blot showing $\mathrm{S} 10$ phosphorylation on $\mathrm{H} 3$ by protein kinase $\mathrm{A}$ (control) incubated phospho H3S10; bottom panel, loading control (Coomassie blue gel staining after SDS-PAGE). c, Representative Western blot wing decreased PP1/HDAC1 interaction in HDAC1 immunoprecipitates in the presence of NIPP1* in vitro (top panel), and in the NIPP1*-EGFP mice when compared with control littermates (nuclear, $n=7$; cytoplasmic, $n=3$ );

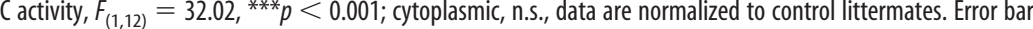
作 noprecipitates between control and mutant mice. Co-IP data are representative of at least three independent experiments.

learning and memory, we generated a transgenic mouse model in which PP1 can be selectively inhibited in the nucleus of forebrain neurons. We hypothesized that the inhibition of the nuclear pool of PP1 should alter histone PTMs in neurons, and have an impact on gene transcription associated with long-term memory. We used a fragment of the nuclear inhibitor of PP1, NIPP1 (termed NIPP1* hereafter) (Jagiello et al., 2000), which contains a PP1 inhibition domain and a nuclear localization signal, but excludes other NIPP1 domains such as those for DNA binding and RNA splicing (Fig. 1a). NIPP $1^{*}$ was expressed inducibly and reversibly under the control of the dox-dependent rtTA2 (Michalon et al., 2005 ) and the CaMKII $\alpha$ promoter (Fig. $1 b$ ). In the resulting double transgenic mice (NIPP $1^{\star}$-EGFP), NIPP $1^{\star}$ was predominantly expressed in major forebrain structures including the hippocampal formation (supplemental Fig. 1a, available at www.jneurosci. org as supplemental material) and cortex, and marginally in the amygdala (Fig. 1c, left panel). It was absent from non-forebrain structures such as the hypothalamus and brainstem (Fig. 1c; sup- 
a

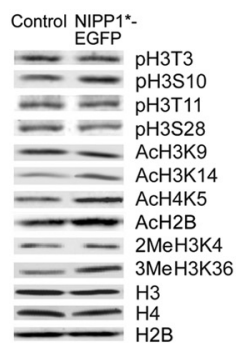

b Histone modifications

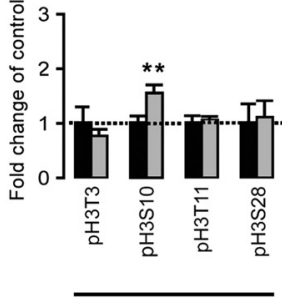

Phosphorylation

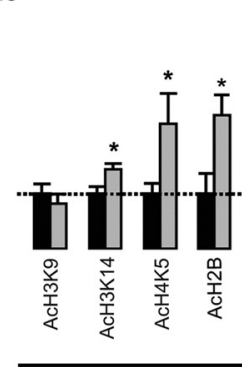

Acetylation
Control NIPP1*-EGFP

known whether this interaction also occurs in the brain in vivo. We first examined whether PP1 associates with the chromatin by coimmunoprecipitation (co-IP) assays using an antibody against PP1 $\gamma$, a nuclear isoform of PP1 (Moorhead et al., 2007). These assays showed that nuclear PP1 does bind to $\mathrm{H} 3$ in the adult mouse forebrain (Fig. $2 a$, control). These results were confirmed with an anti-H3 antibody (data not shown). Next, we tested whether this interaction is functionally important and examined whether it correlates with $\mathrm{H} 3$ dephosphorylation. In vitro, the binding to the chromatin was associated with dephosphorylation of serine 10 ( 110 ) on H3 (Fig. 2b, middle panel), and this dephosphorylation was abolished when PP1 was inhibited by NIPP1 (Fig. 2b, right panel). Notably, in the adult brain, PP1 binding to $\mathrm{H} 3$ was globally not altered by NIPP $1^{\star}$ expression (Fig. $2 a, \mathrm{NIPP}^{\star}{ }^{\star}$-EGFP), probably because the binding of PP1 to the chromatin is not altered overall, but only at specific loci.

Since PP1 was reported to associate with HDACs in vitro (Canettieri et al., 2003; Brush et al., 2004), we next tested whether this association also occurs in the adult brain and whether it is perturbed by NIPP ${ }^{\star}$ expression. Co-IP assays showed that the level of HDAC1 associated with PP1 was decreased by PP1 inhibition, both in vitro and in vivo (Fig. $2 c$ ), and that this correlated with reduced HDAC activity selectively in the nucleus, but not in the cytoplasm of nuclear forebrain extracts (Fig. 2d). Furthermore, because histone phosphorylation and acetylation are known to cross talk with histone methylation and often cooccur with this PTM (Latham and Dent, 2007; Ooi and Wood, 2007), we also tested the association of

plemental Fig. 1b, available at www.jneurosci.org as supplemental material). NIPP ${ }^{\star}$ expression was not induced in the absence of dox (Fig. 1c, right panel). At a subcellular level, NIPP1* was restricted to the nucleus of neuronal cells and was absent from other subcellular compartments (Fig. 1d; supplemental Fig. $1 c$, available at www.jneurosci.org as supplemental material). Consistently, it significantly inhibited PP1 activity only in nuclear, but not cytoplasmic fractions (Fig. 1e). This inhibition was specific to PP1 and did not affect PP2A, a structurally related PP (supplemental Fig. 2, available at www.jneurosci.org as supplemental material).

\section{Nuclear PP1 is part of the epigenetic machinery in the brain}

To determine the involvement of nuclear PP1 in chromatin remodeling in the brain, we tested whether the inhibition of PP1 alters the association of PP1 with the chromatin and the epigenetic machinery, in particular with histone-modifying enzymes. Although in vitro, PP1 was shown to be recruited to histone proteins, specifically H3 (Trinkle-Mulcahy et al., 2006), it is not
PP1 with histone demethylases (HDMs). We observed that PP1 interacts with both JMJD2A and LSD1, but that only its interaction with JMJD2A, and not with LSD1, is reduced by PP1 inhibition (Fig. 2e,f). Although JMJD2A activity could not be measured because no specific assay is available, the reduced interaction with PP1 suggests that its activity might be decreased, similar to HDAC activity. Together, these results strongly suggest that $\mathrm{PP} 1$ inhibition results in the displacement of PP1 from HDAC1 and JMJD2A, and that, further to $\mathrm{H} 3$ phosphorylation, PP1 inhibition alters histone acetylation and methylation.

\section{Inhibition of nuclear PP1 alters multiple histone PTMs}

Based on these biochemical data, we next investigated whether the inhibition of nuclear PP1 alters histone PTMs. We performed a series of Western blot analyses in the hippocampus, a brain area in which NIPP $1^{*}$ expression is abundant in the mutant mice (Fig. 1c). We first tested $\mathrm{H} 3 \mathrm{~S} 10$ phosphorylation, a histone PTM regulated by PP1 in vitro (Hsu et al., 2000; Murnion et al., 2001) and 
induced by contextual fear memory (Chwang et al., 2006, 2007). H3S10 phosphorylation was increased in the mutant mice and remarkably, this increase was specific to S10 and not observed on other $\mathrm{H} 3$ residues including threonine 3 (T3), T11, or S28 (Fig. 3a,b). Moreover, this increased phosphorylation was specific to nuclear proteins and did not occur on synaptic proteins known to be PP1 targets (Soderling and Derkach, 2000) such as GluR1, GluR2, and CaMKII $\alpha$ (supplemental Fig. $3 a, b$, available at www. jneurosci.org as supplemental material). Finally, within the nucleus, phosphorylation was specific to histone proteins since it was not altered on other nuclear proteins including the transcription factor CREB, the chromatin regulators HDAC1 and MeCP2, or the protein kinases MSK1 and ERK/MAPK (supplemental Fig. $3 c, d$, available at www.jneurosci.org as supplemental material). Since both MSK1 and ERK/MAPK need to be phosphorylated to be active (Sweatt, 2001; Arthur, 2008), these results suggest that the increase in $\mathrm{H} 3$ phosphorylation is not attributable to altered kinase activity, but most likely to PP1 inhibition.

Since the interaction between PP1 and $\mathrm{HDAC} 1$ is perturbed, and HDAC activity is decreased by inhibition of nuclear PP1 (Fig. $2 c, d$ ), we next examined whether histone acetylation was also affected. Western blot analyses using anti-acetyl histone antibodies showed that acetylation of $\mathrm{H} 2 \mathrm{~B}, \mathrm{H} 3$ lysine 14 (H3K14), and $\mathrm{H} 4 \mathrm{~K} 5$ was increased in the transgenic mice (Fig. 3a,b). Acetylation of H3K9 was, however, not changed, presumably because of steric hindrance with S10 phosphorylation (Edmondson et al., 2002). Furthermore, based on our observation that $\mathrm{PP} 1$ also interacts with the HDMs JMJD2A and LSD1, we examined H3K36 trimethylation (3meH3K36) and H3K4 dimethylation (2meH3K4), PTMs known to be controlled by these demethylases, respectively (Klose and Zhang, 2007). Trimethylation of H3K36 was significantly increased but dimethylation of $\mathrm{H} 3 \mathrm{~K} 4$ was not changed (Fig. 3a,b), consistent with co-IP results showing that JMJD2A but not LSD1, was displaced from PP1.

To confirm that PP1 is sufficient to induce these histone PTMs, we next tested whether an increase in PP1 activity has an opposite effect. PP1 $\gamma$ was overexpressed in hippocampal slices from control and NIPP $1^{*}$-EGFP animals using a lentiviral vector (supplemental Fig. 4, available at www.jneurosci.org as supplemental material), and the effect on histone PTMs was assessed. Western blot analyses showed that PP $1 \gamma$ overexpression induced a dephosphorylation of H3S10, deacetylation of H3K14 and H4K5, and demethylation of H3K36 (Fig. 3c, d, white bars). These changes were reversed when PP1 $\gamma$ was inhibited by NIPP $1^{*}$ (Fig. $3 c$,d, white/gray striped bars), suggesting that they directly resulted from increased PP1 $\gamma$. H3K9
NFkB promoter histone PTMs

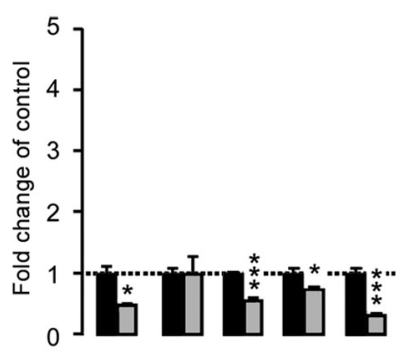

cFos promoter histone PTMs

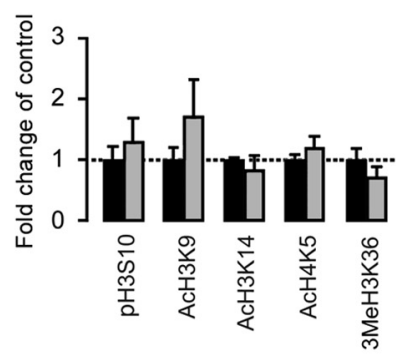

c

RNA Pol II ChIP

d PP1 $1 \gamma \mathrm{ChIP}$

Control NIPP1*-EGFP

Figure 4. Promoter-specific histone PTMs and gene expression are altered by inhibition of nuclear PP1. $\boldsymbol{a}$, ChIP assays showing

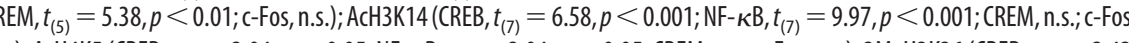

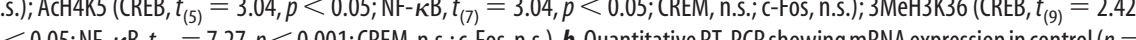
$7-9)$ and NIPP1*-EGFP $(n=5-9)$ mice for CREB $\left(F_{(1,16)}=9.84, p<0.01\right)$, CREM (n.s.), NF- $\kappa B\left(F_{(1,10)}=10.97, p<0.01\right)$, and -6; NIPP1*-EGFP, $n=3-4$; CREB $t_{(6)}=3.07, p<0.05$; (REM, n.S.; NF- $\kappa \mathrm{B}, t_{(6)}=3.82, p<0.05$; c-Fos, n.s.). d, ChIP assays shing PP1 $\gamma$ binding to the promoter region of CREB, CREM, NF- $\kappa$ B, and c-Fos (control, $n=3-4$; NIPP1*-EGFP, $n=3-4$; CREB $t_{(6)}=6.26, p<0.01 ;$ (CREM, n.s.; NF- $\kappa \mathrm{B}, t_{(6)}=3.44, p<0.05 ;$; - Fos, n.s.). Data are normalized to control littermates. Error bars indicate SEM. ${ }^{*} p<0.05,{ }^{* *} p<0.01,{ }^{* * *} p<0.001$.

acetylation and $\mathrm{H} 3 \mathrm{~K} 4$ dimethylation were, however, not changed, consistent with our previous observation that these residues are not altered by PP1 inhibition (Fig. $3 a-d$ ). Together, these results strongly suggest that nuclear PP1 controls multiple PTMs on specific histone residues, most likely through direct (for phosphorylation) and indirect (for acetylation and methylation) mechanisms.

Changes in histone PTMs are associated with altered transcription of genes involved in memory formation

Since histone PTMs contribute to the regulation of transcriptional activity (Jenuwein and Allis, 2001; Kouzarides, 2007; Li et al., 2007), we examined whether the changes in PTMs induced by inhibition of nuclear PP1 occur at the promoter of genes important for memory formation and whether the expression of these genes is altered. We conducted a series of ChIP assays on the promoter of four representative genes, CREB [a transcription factor required for memory formation (Silva et al., 1998)], nuclear factor- $\kappa \mathrm{B}(N F-\kappa B)$ [a transcriptional regulator involved in 
a Long-term object recognition

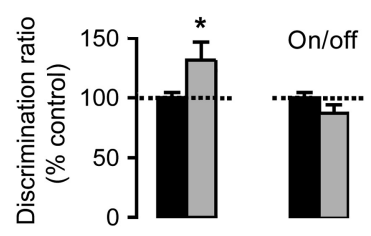

C Long-term spatial memory

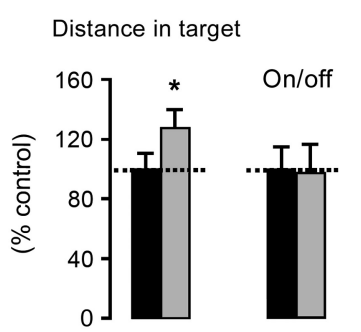

b Short-term object recognition

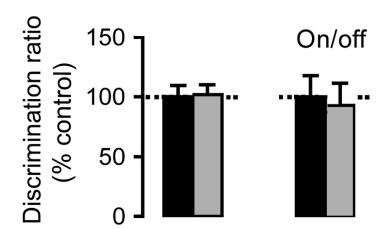

the CREM and c-Fos promoter (Fig. $4 d$ ). These results overall suggest that the presence of PP1 at the chromatin regulates gene transcription through histone PTMs.

Control NIPP1*-EGFP

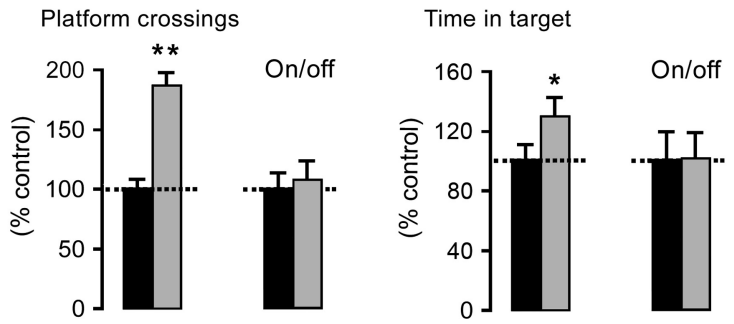

Figure 5. Object recognition and spatial memory are improved by inhibition of nuclear PP1. $\boldsymbol{a}, 0$ bject discrimination ratio in NIPP1*-EGFP $(n=8)$ and control littermates $(n=10)$ treated with dox $\left(F_{(1,16)}=5.82, p<0.05\right)$ (left panel) and in NIPP1*-EGFP $(n=7)$ and control littermates $(n=6)$ on/off dox (n.s.) $1 \mathrm{~d}$ after training (right panel). $\boldsymbol{b}$, Object discrimination ratio in $\operatorname{NIPP} 1^{*}$-EGFP $(n=8)$ and control littermates $(n=7)$ treated with dox (n.s.) (left panel) and in NIPP1*-EGFP $(n=6)$ and control littermates $(n=6)$ on/offdox (n.s.) 10 min after training (right panel).c, Left panels, Spatial memory on the water maze evaluated by the distance traveled in the target quadrant in NIPP1*-EGFP $(n=7)$ and control littermates $(n=8)$ treated with dox $\left(F_{(1,13)}=\right.$ 5.39; $p<0.05$ ) (left) and in NIPP1*-EGFP $(n=3)$ and control littermates $(n=6)$ on/off dox (n.s.) (right) $1 \mathrm{~d}$ after the end of training. Middle panels, Spatial memory measured by the number of platform crossings in NIPP1*-EGFP $(n=7)$ and control littermates treated with dox $(n=8)\left(F_{(1,13)}=12.05 ; p<0.01\right)$ (left) and in NIPP1*-EGFP $(n=3)$ and control littermates $(n=$ 6) on/off dox (n.s.) (right) $1 \mathrm{~d}$ after the end of training. Right panels, Spatial memory measured by time spent in target quadrant in NIPP1*-EGFP $(n=7)$ and control littermates treated with dox $(n=8)\left(F_{(1,13)}=5.93 ; p<0.05\right)($ left $)$ and in NIPP1*-EGFP $(n=$ 3 ) and control littermates $(n=6)$ on/off dox (right) $1 \mathrm{~d}$ after the end of training; behavioral data are representative of a minimum of two experiments on each task using independent groups of mice. Error bars indicate SEM. ${ }^{*} p<0.05$, ${ }^{* *} p<0.01$.

long-term memory (Meffert and Baltimore, 2005)], cAMPresponsive element modulator (CREM) (a modulator of CREB functions), and c-fos (an immediate-early gene), followed by mRNA analyses by quantitative RT-PCR. ChIP assays revealed that $\mathrm{H} 3 \mathrm{~S} 10$ phosphorylation, $\mathrm{H} 3 \mathrm{~K} 14$ and $\mathrm{H} 4 \mathrm{~K} 5$ acetylation, and $\mathrm{H} 3 \mathrm{~K} 36$ trimethylation were increased at the CREB promoter, but decreased at the NF- $\kappa$ B promoter (Fig. $4 a$ ). This was accompanied by increased mRNA expression of CREB but decreased expression of NF- $\kappa \mathrm{B}$ (Fig. $4 b$ ). With the exception of hypoacetylation of $\mathrm{H} 3 \mathrm{~K} 9$ at the CREM promoter, no significant change in histone PTMs was observed at the CREM or c-Fos promoter, consistent with the observation that the mRNA expression of these genes was not changed (Fig. $4 a, b$ ). The observation that $\mathrm{H} 3 \mathrm{~K} 9$ acetylation was reduced in the promoter region of CREM, but the mRNA expression unchanged, suggests that $\mathrm{H} 3 \mathrm{~K} 9$ acetylation has no significant impact on CREM expression.

Consistent with the gene expression data, ChIP assays further demonstrated that the occupancy of RNA Pol II was increased at the CREB promoter but decreased at the NF- $\kappa \mathrm{B}$ promoter, although not changed at the CREM and c-Fos promoter (Fig. 4c). These results confirm a link between the effect of histone PTMs on chromatin decondensation, RNA Pol II binding, and gene transcription. Finally, although the binding of PP1 to H3 was overall not altered by inhibition of nuclear PP1 (Fig. 2a), we examined whether PP1 binding is altered at specific promoters in correlation with the changes in histone PTMs. We measured PP1 occupancy at the CREB, NF- $\kappa \mathrm{B}, \mathrm{CREM}$, and $\mathrm{c}$-Fos promoter by ChIP assays, and found that PP1 binding correlates with changes in histone PTMs. It was almost absent at the CREB promoter, but significantly increased at the NF- $\kappa \mathrm{B}$ promoter and not changed at and not after $10 \mathrm{~min}$, indicating a selective effect on LTM (Fig. 5b; supplemental Fig. 5b, available at www. jneurosci.org supplemental material). This effect was confirmed on another form of hippocampus-dependent LTM, spatial memory, using a water maze. On this task, mice need to learn and remember distal cues around a circular tank filled with opaque water to find an invisible escape platform. Mutant mice and control littermates had comparable performance during acquisition (supplemental Fig. $5 c$, available at www.jneurosci.org as supplemental material). However, $1 \mathrm{~d}$ after training, mutant mice covered a longer distance, had a more precise search (increased platform crossings), and spent more time searching for the platform in the target quadrant than control littermates (Fig. $5 c$; supplemental Fig. $5 d, e$, available at www.jneurosci.org as supplemental material), suggesting improved long-term spatial memory. Importantly, for both object recognition and spatial memory, the improvement was not observed in the absence of NIPP1* (mutant off) (supplemental Fig. 5b, d,e, available at www.jneurosci.org as supplemental material) or when NIPP1* expression was suppressed by dox withdrawal (on/off) (Fig. 5), suggesting a direct effect of PP1 inhibition. Furthermore, the memory improvement was not attributable to any change in overall exploratory activity since total movement, time spent in center, and rearing behavior in an open field were similar in mutant mice and control littermates (supplemental Fig. $5 f$, available at www.jneurosci.org as supplemental material). Together, these results indicate that inhibition of nuclear PP1 improves several forms of LTM.

\section{Specific histone PTMs are induced in LTM}

Finally, to determine whether the epigenetic changes associated with inhibition of nuclear PP1 are relevant to memory formation, 
we examined their correlation with LTM using a new group of animals on the object recognition test. We focused on histone PTMs at the CREB promoter because CREB is specifically linked to long-term memory (Silva et al., 1998; Josselyn et al., 2001) and conducted a series of ChIP assays in the hippocampus $24 \mathrm{~h}$ after training. In control mice, H3S10 phosphorylation and $\mathrm{H} 3 \mathrm{~K} 14$ acetylation were increased in correlation with LTM, whereas $\mathrm{H} 3 \mathrm{~K} 9$ and $\mathrm{H} 4 \mathrm{~K} 5$ acetylation, and H3K36 trimethylation were not changed in the promoter region of CREB (Fig. $6 a$, black lines; supplemental Fig. 6, available at www.jneurosci.org as supplemental material). This increase correlated with enhanced CREB expression (Fig. 6b, black bars), suggesting a link between these histone PTMs, CREB expression, and LTM. In the mutant mice, H3S10 phosphorylation and H3K14 acetylation were also increased $24 \mathrm{~h}$ after training, but significantly more than in control mice (Fig. $6 a$, gray lines). In addition to $\mathrm{H} 3 \mathrm{~S} 10$ phosphorylation and H3K14 acetylation, H3K36 trimethylation was also significantly enhanced after training, whereas H3K9 and H4K5 acetylation was decreased. Importantly, however, the net difference in histone PTMs observed in the mutant mice before training persisted for H3S10 phosphorylation, H3K14/ H4K5 acetylation, and H3K36 trimethylation after training and correlated with a significant increase in CREB expression and LTM when compared with control mice (Fig. 6b). Finally, CREB phosphorylation at S133 was also higher in the mutant mice after training (Fig. $6 c$ ), consistent with previous findings that CREB phosphorylation is activity dependent and induced in LTM (Silva et al., 1998). Overall, these results suggest that H3S10 phosphorylation and H3K14 acetylation at the CREB promoter correlate with CREB expression and that, in combination with H4K5 acetylation and H3K36 trimethylation, they further potentiate CREB expression and improve LTM.

\section{Discussion}

The present findings reveal that the nuclear pool of the protein phosphatase PP1 in adult neurons plays a key role in the epigenetic regulation of memory formation in mammals. They demonstrate for the first time that nuclear PP1 is present at the chromatin in brain cells, in which it regulates histone PTMs by acting both directly and through complexes with components of the epigenetic machinery including HDAC1 and JMJD2A. The selective inhibition of nuclear PP1 in neurons not only interferes with the activity of PP1 but also with these complexes and, consequently, alters multiple histone PTMs including phosphorylation, acetylation, and methylation at the promoter of specific genes like CREB and NF- $\kappa$ B. This, in turn, alters the expression of these genes and is associated with improved LTM.

Overall, the present data highlight the importance of combi- natorial histones PTMs for the regulation of memory genes and demonstrates that they are controlled by PP1. Further to revealing a hitherto-unknown role for PP1 in neuronal cells, the data show that nuclear PP1 has distinct functions from synaptic PP1 (Hu et al., 2006; Jouvenceau et al., 2006; Mansuy and Shenolikar, 2006) and underscore the importance of PP1 in multiple fundamental cellular processes and of its subcellular compartmentalization (Virshup and Shenolikar, 2009). These results significantly extend recent reports showing that the protein kinases MSK1, ERK/MAPK, and $\mathrm{I} \kappa \mathrm{B}$ are involved in the control of histone PTMs in memory (Levenson et al., 2004; Chwang et al., 2006, 2007; Lubin and Sweatt, 2007) and suggest that PP1 is the primary PP that counteracts these kinases. Together, they strengthen the concept that the balance between protein kinases and phosphatases in the brain is critical for cognitive processes (Lee and Silva, 2009) by showing that this balance also operates at the level of the chromatin.

This study is also the first to demonstrate the combinatorial and simultaneous regulation of histone phosphorylation, acetylation, and methylation, three PTMs known to be induced by learning (Guan et al., 2002; Alarcón et al., 2004; Levenson et al., 2004; Chwang et al., 2006, 2007; Bredy et al., 2007; Fischer et al., 2007; Lubin and Sweatt, 2007; Lubin et al., 2008), by PP1- 

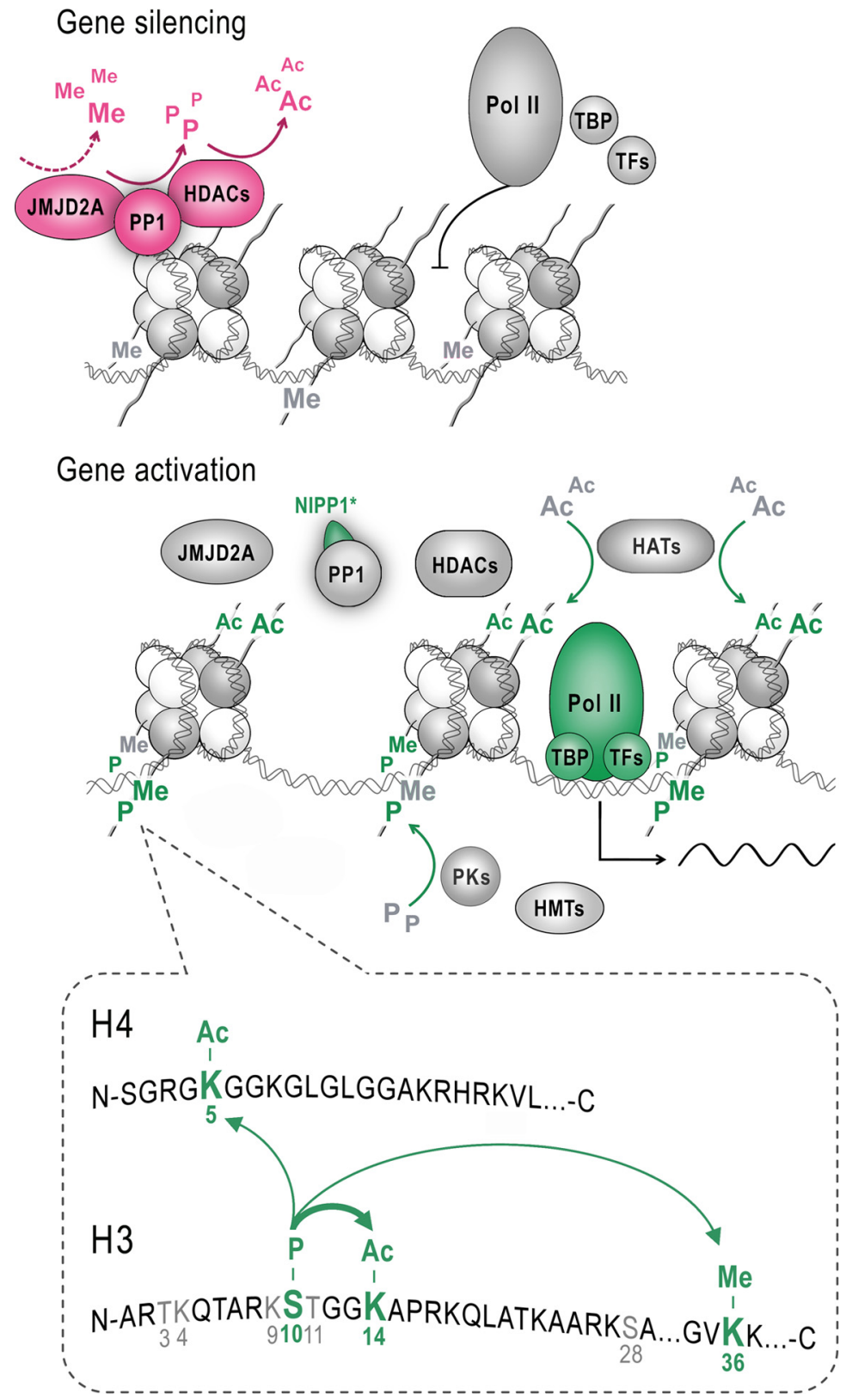

Figure 7. Model for a PP1-dependent histone code for the control of gene transcription. For gene silencing, PP1 binds to the chromatin where it dephosphorylates histones and negatively controls histone acetylation and methylation through association with HDACs and JMJD2A. These changes enhance chromatin condensation and prevent RNA polymerasell (PoI II), TATA box binding protein (TBP), and other transcription factors (TFs) from binding to the chromatin. For gene activation, PP1 is inhibited by endogenous inhibitors such as NIPP1* or targeting partners. This favors histone phosphorylation (specifically on H3S10), which is mediated by protein kinases (PKs) such as MSK1, ERK1, or PKA (Canettieri et al., 2003; Chwang et al., 2006, 2007). PP1 inhibition further leads to the dissociation of PP1 from HDACs, which reduces HDAC activity and thus increases histone acetylation (specifically on H3K14 and H4K5), most likely with the aid of HATs such as (BP (Alarcón et al., 2004; Korzus et al., 2004) and p300 (Oliveira et al., 2007). These changes are accompanied by an increase in methylation of H3K36, which is likely to result from a reduced interaction between PP1 and JMJD2A and a subsequent reduction in the activity of JMJD2A. Other members of the epigenetic machinery such as histone methyltransferases (HMTs) are presumably also involved. Together, these changes trigger chromatin decondensation and increase its accessibility to the transcriptional machinery. Bottom part, in gray, histone residues assessed for PTMs but not found to be differentially regulated; in green, histone PTMs, which depend on nuclear PP1. The thick arrow represents a well established cross talk between $\mathrm{H} 3 \mathrm{~S} 10$ phosphorylation and $\mathrm{H} 3 \mathrm{~K} 14$ acetylation in the context of memory formation (Chwang et al., 2006, 2007). The thin arrows illustrate potential cross talks suggested by the present data. For clarity, the cross talk between these residues and the acetylated H2B is omitted. Note that some of these cross talks have been reported in other model organisms (Kouzarides, 2007; Latham and Dent, 2007), but not in the adult mammalian brain.

dependent mechanisms. It shows that gene transcription (e.g., for CREB) and LTM are facilitated by H3S10 phosphorylation, and H3K14 and H2B acetylation (Alarcón et al., 2004; Levenson et al., 2004; Chwang et al., 2006, 2007), as well as by H4K5 acetylation and H3K36 trimethylation, two newly identified PTMs. This transcriptional signature appears to be controlled by cross talk mechanisms between these histone PTMs that are coordinated by PP1 (Fig. 7). Our data further suggest that these histone PTMs may not all be required for the activation of CREB transcription since, in control mice, only $\mathrm{H} 3 \mathrm{~S} 10$ phosphorylation and H3K14 acetylation correlate with increased gene expression. However, a full combination may be needed to further raise or prolong gene transcription, possibly through more sustained decondensation of the chromatin. In this respect, histone methylation may be of particular importance since this PTM is implicated in the maintenance of the transcriptional status of genes (Shilatifard, 2006) and could thus contribute to the stability of transcriptional signatures in LTM. However, it is important to note that, although our data identify one such signature at the CREB promoter, other signatures on other genes likely also exist. Finally, it should be noted that the decrease in $\mathrm{H} 4 \mathrm{~K} 5$ and $\mathrm{H} 3 \mathrm{~K} 9$ acetylation induced by training in the mutant mice is mechanistically not understood but may involve a negative cis-cross talk between histone PTMs from S10 to $\mathrm{K} 9$ on $\mathrm{H} 3$ (Edmondson et al., 2002) and, likewise, a yet-unidentified trans-cross talk between H3S10 and H4K5 (Fig. 7).

The mechanisms that target PP1 and control its activity at the chromatin are not fully elucidated but are likely to involve the association of PP1 with specific binding partners such as PNUTS (phosphatase 1 nuclear targeting subunit) in neurons (Ceulemans and Bollen, 2004; Bennett, 2005). Importantly, in the mutant mice, the substrate specificity of nuclear PP1 was apparently not disturbed by PP1 inhibition since the phosphorylation of nonhistone nuclear proteins or of synaptic proteins was not altered-only CREB phosphorylation after training was increased, consistent with the fact that this PTM is activity dependent (Silva et al., 1998). This specificity is thought to result from the endogenous nature of NIPP $1^{*}$, which is a fragment of a natural inhibitor that targets PP1 specifically without interfering with its subcellular localization. Its moderate expression achieved by our transgenic system induced a physiological range of PP1 inhibition (40-60\%) (Genoux et al., 2002), which most likely avoids off-target effects. In this respect, the observation that HDAC1 phosphorylation (on S421) was not altered despite its close association with PP1, suggests that this residue is not dephosphorylated by PP1 in neurons. Since HDAC1 and PP1 are both fully functional when phys- 
ically associated in an enzymatic complex (Canettieri et al., 2003), the decrease in HDAC activity may result from the complex being disrupted upon nuclear PP1 inhibition. This is reminiscent of the observation that HDAC inhibitors such as TSA (trichostatin A) also disrupt HDAC-PP1 complexes and thereby downregulate HDAC activity (Brush et al., 2004).

Together, the present data identify a novel mechanism for chromatin remodeling and epigenetic regulation of LTM formation that depends on nuclear PP1. They demonstrate that, through phosphatase inhibition, this mechanism is amenable to positive modulation for memory improvement, which expands previous reports showing that memory defects and cognitive decline caused by perturbed chromatin remodeling can be improved by HDAC inhibition (Abel and Zukin, 2008). These findings may therefore provide new potential targets for the application of "epigenetic medicine" for treating memory disorders and cognitive decline.

\section{References}

Abel T, Zukin RS (2008) Epigenetic targets of HDAC inhibition in neurodegenerative and psychiatric disorders. Curr Opin Pharmacol 8:57-64.

Alarcón JM, Malleret G, Touzani K, Vronskaya S, Ishii S, Kandel ER, Barco A (2004) Chromatin acetylation, memory, and LTP are impaired in CBP $+/-$ mice: a model for the cognitive deficit in Rubinstein-Taybi syndrome and its amelioration. Neuron 42:947-959.

Arthur JS (2008) MSK activation and physiological roles. Front Biosci 13:5866-5879.

Bennett D (2005) Transcriptional control by chromosome-associated protein phosphatase-1. Biochem Soc Trans 33:1444-1446.

Beullens M, Van Eynde A, Stalmans W, Bollen M (1992) The isolation of novel inhibitory polypeptides of protein phosphatase 1 from bovine thymus nuclei. J Biol Chem 267:16538-16544.

Bredy TW, Wu H, Crego C, Zellhoefer J, Sun YE, Barad M (2007) Histone modifications around individual BDNF gene promoters in prefrontal cortex are associated with extinction of conditioned fear. Learn Mem 14:268-276.

Broadbent NJ, Squire LR, Clark RE (2004) Spatial memory, recognition memory, and the hippocampus. Proc Natl Acad Sci US A 101: 14515-14520.

Brush MH, Guardiola A, Connor JH, Yao TP, Shenolikar S (2004) Deactylase inhibitors disrupt cellular complexes containing protein phosphatases and deacetylases. J Biol Chem 279:7685-7691.

Canettieri G, Morantte I, Guzmán E, Asahara H, Herzig S, Anderson SD, Yates JR 3rd, Montminy M (2003) Attenuation of a phosphorylationdependent activator by an HDAC-PP1 complex. Nat Struct Biol 10:175-181.

Ceulemans H, Bollen M (2004) Functional diversity of protein phosphatase-1, a cellular economizer and reset button. Physiol Rev 84:1-39.

Ceulemans H, Stalmans W, Bollen M (2002) Regulator-driven functional diversification of protein phosphatase-1 in eukaryotic evolution. Bioessays 24:371-381.

Chakrabarti SK, James JC, Mirmira RG (2002) Quantitative assessment of gene targeting in vitro and in vivo by the pancreatic transcription factor, Pdxl. Importance of chromatin structure in directing promoter binding. J Biol Chem 277:13286-13293.

Chwang WB, O’Riordan KJ, Levenson JM, Sweatt JD (2006) ERK/MAPK regulates hippocampal histone phosphorylation following contextual fear conditioning. Learn Mem 13:322-328.

Chwang WB, Arthur JS, Schumacher A, Sweatt JD (2007) The nuclear kinase mitogen- and stress-activated protein kinase 1 regulates hippocampal chromatin remodeling in memory formation. J Neurosci 27:12732-12742.

Duman RS, Newton SS (2007) Epigenetic marking and neuronal plasticity. Biol Psychiatry 62:1-3.

Edmondson DG, Davie JK, Zhou J, Mirnikjoo B, Tatchell K, Dent SY (2002) Site-specific loss of acetylation upon phosphorylation of histone H3. J Biol Chem 277:29496-29502.

Fischer A, Sananbenesi F, Wang X, Dobbin M, Tsai LH (2007) Recovery of learning and memory is associated with chromatin remodelling. Nature 447:178-182.

Genoux D, Haditsch U, Knobloch M, Michalon A, Storm D, Mansuy IM
(2002) Protein phosphatase 1 is a molecular constraint on learning and memory. Nature 418:970-975.

Guan Z, Giustetto M, Lomvardas S, Kim JH, Miniaci MC, Schwartz JH, Thanos D, Kandel ER (2002) Integration of long-term-memory-related synaptic plasticity involves bidirectional regulation of gene expression and chromatin structure. Cell 111:483-493.

Hédou GF, Koshibu K, Farinelli M, Kilic E, Gee CE, Kilic U, Baumgärtel K, Hermann DM, Mansuy IM (2008) Protein phosphatase 1-dependent bidirectional synaptic plasticity controls ischemic recovery in the adult brain. J Neurosci 28:154-162.

Hsu JY, Sun ZW, Li X, Reuben M, Tatchell K, Bishop DK, Grushcow JM, Brame CJ, Caldwell JA, Hunt DF, Lin R, Smith MM, Allis CD (2000) Mitotic phosphorylation of histone $\mathrm{H} 3$ is governed by Ipl1/aurora kinase and Glc7/PP1 phosphatase in budding yeast and nematodes. Cell 102:279-291.

Hu XD, Huang Q, Roadcap DW, Shenolikar SS, Xia H (2006) Actin-associated neurabin-protein phosphatase-1 complex regulates hippocampal plasticity. J Neurochem 98:1841-1851.

Jaenisch R, Bird A (2003) Epigenetic regulation of gene expression: how the genome integrates intrinsic and environmental signals. Nat Genet 33: 245-254.

Jagiello I, Van Eynde A, Vulsteke V, Beullens M, Boudrez A, Keppens S, Stalmans W, Bollen M (2000) Nuclear and subnuclear targeting sequences of the protein phosphatase-1 regulator NIPP1. J Cell Sci 113: 3761-3768.

Jenuwein T, Allis CD (2001) Translating the histone code. Science 293:1074-1080.

Jin Q, van Eynde A, Beullens M, Roy N, Thiel G, Stalmans W, Bollen M (2003) The protein phosphatase-1 (PP1) regulator, nuclear inhibitor of PP1 (NIPP1), interacts with the polycomb group protein, embryonic ectoderm development (EED), and functions as a transcriptional repressor. J Biol Chem 278:30677-30685.

Josselyn SA, Shi C, Carlezon WA Jr, Neve RL, Nestler EJ, Davis M (2001) Long-term memory is facilitated by cAMP response element-binding protein overexpression in the amygdala. J Neurosci 21:2404-2412.

Jouvenceau A, Hédou G, Potier B, Kollen M, Dutar P, Mansuy IM (2006) Partial inhibition of PP1 alters bidirectional synaptic plasticity in the hippocampus. Eur J Neurosci 24:564-572.

Klose RJ, Zhang Y (2007) Regulation of histone methylation by demethylimination and demethylation. Nat Rev Mol Cell Biol 8:307-318.

Knobloch M, Farinelli M, Konietzko U, Nitsch RM, Mansuy IM (2007) A $\beta$ oligomer-mediated long-term potentiation impairment involves protein phosphatase 1-dependent mechanisms. J Neurosci 27:7648-7653.

Korzus E, Rosenfeld MG, Mayford M (2004) CBP histone acetyltransferase activity is a critical component of memory consolidation. Neuron 42:961-972.

Kouzarides T (2007) Chromatin modifications and their function. Cell 128:693-705.

Latham JA, Dent SY (2007) Cross-regulation of histone modifications. Nat Struct Mol Biol 14:1017-1024.

Lee YS, Silva AJ (2009) The molecular and cellular biology of enhanced cognition. Nat Rev Neurosci 10:126-140.

Levenson JM, O’Riordan KJ, Brown KD, Trinh MA, Molfese DL, Sweatt JD (2004) Regulation of histone acetylation during memory formation in the hippocampus. J Biol Chem 279:40545-40559.

Li B, Carey M, Workman JL (2007) The role of chromatin during transcription. Cell 128:707-719.

Livak KJ, Schmittgen TD (2001) Analysis of relative gene expression data using real-time quantitative PCR and the $2(-$ delta delta $\mathrm{C}(\mathrm{T}))$ method. Methods 25:402-408.

Lubin FD, Sweatt JD (2007) The IkappaB kinase regulates chromatin structure during reconsolidation of conditioned fear memories. Neuron 55:942-957.

Lubin FD, Roth TL, Sweatt JD (2008) Epigenetic regulation of BDNF gene transcription in the consolidation of fear memory. J Neurosci 28:10576-10586.

Malleret G, Haditsch U, Genoux D, Jones MW, Bliss TV, Vanhoose AM, Weitlauf C, Kandel ER, Winder DG, Mansuy IM (2001) Inducible and reversible enhancement of learning, memory, and long-term potentiation by genetic inhibition of calcineurin. Cell 104:675-686.

Mansuy IM, Shenolikar S (2006) Protein serine/threonine phosphatases in 
neuronal plasticity and disorders of learning and memory. Trends Neurosci 29:679-686.

Meffert MK, Baltimore D (2005) Physiological functions for brain NFkappaB. Trends Neurosci 28:37-43.

Michalon A, Koshibu K, Baumgärtel K, Spirig DH, Mansuy IM (2005) Inducible and neuron-specific gene expression in the adult mouse brain with the rtTA2S-M2 system. Genesis 43:205-212.

Miller CA, Sweatt JD (2007) Covalent modification of DNA regulates memory formation. Neuron 53:857-869.

Miller CA, Campbell SL, Sweatt JD (2008) DNA methylation and histone acetylation work in concert to regulate memory formation and synaptic plasticity. Neurobiol Learn Mem 89:599-603.

Moorhead GB, Trinkle-Mulcahy L, Ulke-Lemée A (2007) Emerging roles of nuclear protein phosphatases. Nat Rev Mol Cell Biol 8:234-244.

Murnion ME, Adams RR, Callister DM, Allis CD, Earnshaw WC, Swedlow JR (2001) Chromatin-associated protein phosphatase 1 regulates aurora-B and histone H3 phosphorylation. J Biol Chem 276:26656-26665.

Oliveira AM, Wood MA, McDonough CB, Abel T (2007) Transgenic mice expressing an inhibitory truncated form of $\mathrm{p} 300$ exhibit long-term memory deficits. Learn Mem 14:564-572.

Ooi L, Wood IC (2007) Chromatin crosstalk in development and disease: lessons from REST. Nat Rev Genet 8:544-554.

Shilatifard A (2006) Chromatin modifications by methylation and ubiquitination: implications in the regulation of gene expression. Annu Rev Biochem 75:243-269.

Silva AJ, Kogan JH, Frankland PW, Kida S (1998) CREB and memory. Annu Rev Neurosci 21:127-148.
Soderling TR, Derkach VA (2000) Postsynaptic protein phosphorylation and LTP. Trends Neurosci 23:75-80.

Swank MW, Sweatt JD (2001) Increased histone acetyltransferase and lysine acetyltransferase activity and biphasic activation of the ERK/RSK cascade in insular cortex during novel taste learning. J Neurosci 21:3383-3391.

Sweatt JD (2001) The neuronal MAP kinase cascade: a biochemical signal integration system subserving synaptic plasticity and memory. J Neurochem 76:1-10.

Szulc J, Wiznerowicz M, Sauvain MO, Trono D, Aebischer P (2006) A versatile tool for conditional gene expression and knockdown. Nat Methods 3:109-116.

Trinkle-Mulcahy L, Andersen J, Lam YW, Moorhead G, Mann M, Lamond AI (2006) Repo-Man recruits PP1 gamma to chromatin and is essential for cell viability. J Cell Biol 172:679-692.

Tsankova N, Renthal W, Kumar A, Nestler EJ (2007) Epigenetic regulation in psychiatric disorders. Nat Rev Neurosci 8:355-367.

Tsankova NM, Kumar A, Nestler EJ (2004) Histone modifications at gene promoter regions in rat hippocampus after acute and chronic electroconvulsive seizures. J Neurosci 24:5603-5610.

Vecsey CG, Hawk JD, Lattal KM, Stein JM, Fabian SA, Attner MA, Cabrera SM, McDonough CB, Brindle PK, Abel T, Wood MA (2007) Histone deacetylase inhibitors enhance memory and synaptic plasticity via CREB:CBP-dependent transcriptional activation. J Neurosci 27:61286140.

Virshup DM, Shenolikar S (2009) From promiscuity to precision: protein phosphatases get a makeover. Mol Cell 33:537-545.

Williams SK, Tyler JK (2007) Transcriptional regulation by chromatin disassembly and reassembly. Curr Opin Genet Dev 17:88-93. 